\title{
Maternal mortality in a tertiary care hospital: a 3-year retrospective study
}

\author{
Harish K. M. ${ }^{1}$, Shwetha N. ${ }^{1 *}$, Nalini N. ${ }^{2}$
}

\begin{abstract}
${ }^{1}$ Department of Obstetrics and Gynaecology, The Apollo Medical College, Chittoor, Andhra Pradesh, India ${ }^{2}$ Department of Obstetrics and Gynaecology, Govt. District Hospital, Ramanagara, Karnataka, India
\end{abstract}

Received: 09 December 2020

Accepted: 24 December 2020

\author{
*Correspondence: \\ Dr. Shwetha N., \\ E-mail: shwethanarasappa@gmail.com
}

Copyright: ( $)$ the author(s), publisher and licensee Medip Academy. This is an open-access article distributed under the terms of the Creative Commons Attribution Non-Commercial License, which permits unrestricted non-commercial use, distribution, and reproduction in any medium, provided the original work is properly cited.

\begin{abstract}
Background: Systematic review to determine the epidemiological aspects and causes of maternal mortality there by exploring possibility of intervention and implementing Evidence-based health policies and programmes to prevent future maternal death. Aims and objectives of the study were to calculate the maternal mortality rate in our hospital, to assess the epidemiological aspects of maternal mortality, to assess the type of delay and causes of maternal mortality and to suggest ways to reduce the MMR.

Methods: This is a 3-year retrospective study from January 2017 to December 2019 that will be conducted in the department of obstetrics and gynaecology, The Apollo medical college and District hospital, Chittoor a tertiary care teaching hospital situated in the southernmost part of Andhra Pradesh state in India. It gets a large number of referrals from PHCs, CHCs, and maternity homes as well as from hospitals across Chittoor district. Epidemiological data will be collected from the hospital register. Maternal mortality ratio, epidemiological factors and causes affecting maternal mortality are assessed.

Results: MMR in present study was 66 per 1,00,000 live births. Women in the age group of 20 to 30 years (85.72\%), illiteracy $(57.16 \%)$ and low socioeconomic status $(100 \%)$ were risk factors for maternal mortality. Obstetric haemorrhage $(57.16 \%)$ is most common cause whereas type 1 and type 2 delays are most common contributing factors for maternal mortality.

Conclusions: Early identification and management of pregnancy complication, strengthening of existing Emergency obstetric care (EmOC) facilities, easy transport and appropriate referral linkages are keys to reduce maternal mortality to further extent.
\end{abstract}

Keywords: Maternal mortality ratio, Maternal mortality, Prevention

\section{INTRODUCTION}

Women are strong pillars of any vibrant society. Sustained development of country can thus be achieved only if we take holistic care of our women and children. Maternal health is an important aspect for development of any country in terms of increasing equity and reducing poverty. The survival and wellbeing of mother is not only important in their own right but are also central to solving larger broader economic, social and developmental challenges. $^{1}$
Every day in 2017, approximately 810 women died from preventable causes related to pregnancy and childbirth. Between 2000 and 2017, the maternal mortality ratio (MMR, number of maternal deaths per 100,000live births) dropped by about $38 \%$ worldwide. $94 \%$ of all maternal deaths occur in low and lower middle-income countries. The MMR in low-income countries in 2017 is 462 per 100000 live births versus 11 per 100000 live births in high income countries. A woman's lifetime risk of maternal death in high income countries is 1 in 5400, versus 1 in 45 in low-income countries. ${ }^{2}$ 
India being a developing country, maternal mortality ratio was exceptionally high in 1990 with 556 women dying during child birth per $1,00,000$ live births. Approximately, 1.38 lakh women are dying every year on account of complications related to pregnancy and child birth. The global MMR at time was much lower at 385 . There has however, been an accelerated decline in MMR in India. MMR in the country has declined 130 in 201416 to 122 in 2015-17 and further decline to 113 in 201618. The number of maternal death stands reduced by $78 \%$. India's share among global maternal death has declined significantly as per United nations maternal mortality estimation inter-agency group (UN- MMEIG) report. $^{3}$

In India, Assam continues to be the state of highest MMR (229). NHP (national health policy) 2017, target for MMR of less than 100 per 1,00,000 live births by 2020 has already been achieved by Andhra Pradesh state of India way back in 2015-17. ${ }^{3}$

The reduction of maternal deaths is a high priority for India, especially in view of the increased attention on the target 3.1 of United nations sustainable development goals (UN SDGs, also known as the global goals) in which all UN member states have agreed to work towards reducing the global maternal mortality ratio to less than 70 per 100000 live births to be achieved by $2030 .^{4}$

Aims of study were to calculate maternal mortality rate in our hospital, to assess epidemiological aspects of maternal mortality to assess type of delay and causes of maternal mortality and to suggest ways to reduce MMR.

\section{METHODS}

This retrospective study was carried out in department of obstetrics and gynaecology, The Apollo medical college and district government hospital, Chittoor, which is a tertiary care center of southern Andhra Pradesh. The hospital gets a large number of referrals from PHCs, CHCs, and maternity homes as well as from hospitals across Chittoor district and has an annual delivery rate of around 4000-5000. The hospital runs 1 ICU and 1 obstetric HDU, one blood bank and 2 emergency operation theatres round the clock to provide emergency obstetric services and critical care to their patients. Details of all the maternal deaths which met the WHO criteria for maternal death, from January 2017 to December 2019 were collected from the individual case sheets and maternal death review forms. These forms were filled by the treating doctor and reviewed by the supervising faculty within 24 hours of the death of women. The maternal death was then analysed and audited weekly, followed by a monthly meeting in department by the senior faculty members. This was later followed by a quarterly meet in hospital, with experts from different fields of medicine and also a quarterly meet in district and state.
These data were analysed with respect to the following parameters: age, parity, gestational age, socioeconomic status (modified Kuppuswamy and Udai Pareekh's scale, residence, booking status, condition of admission, prevalence of anaemia as per WHO anaemia scale, referral status, causes of death according to WHO application of ICD-10 and type of delays identified according to maternal death review forms. ${ }^{5,6}$

Maternal deaths were carefully studied and analysed. Maternal mortality ratio for the study period was calculated using the formula:

\section{Total no of maternal deaths X 1,00,000 \\ MMR = - - $\quad$ Total no of live births}

Types of delay according to maternal death review form is summarized as follows: type I delay-delay in decision making to seek help. Type II delay-delay in transport due to unavailability of vehicles and delay in referral and type III-delay in treatment at institutional level.

\section{RESULTS}

Table 1 show that there were 10491 live births and 7 maternal deaths during the study period from January 2017 to December 2019. MMR in present study for per lakh live birth is 61, 67 and 69 during 2017, 2018 and 2019 respectively. Overall MMR during the study period was 66 per 1,00,000 live births.

Table 1: Year-wise maternal mortality ratio.

\begin{tabular}{|llll|} 
Year & $\begin{array}{l}\text { Total } \\
\text { live birth }\end{array}$ & $\begin{array}{l}\text { Maternal } \\
\text { death }\end{array}$ & $\begin{array}{l}\text { MMR/10,0,000 } \\
\text { live birth }\end{array}$ \\
\hline $\mathbf{2 0 1 7}$ & 3258 & 2 & 61.38 \\
\hline $\mathbf{2 0 1 8}$ & 2942 & 2 & 67.67 \\
\hline $\mathbf{2 0 1 9}$ & 4291 & 3 & 69.91 \\
\hline total & 10491 & 7 & 66.72 \\
\hline
\end{tabular}

The demographic profile and epidemiological characteristics of maternal deaths in Table 2 shows that majority of women who died $(85.72 \%)$ were in the prime reproductive years (21-30 years). More than two-third of women were multipara (71.42\%). Majority of the women were illiterate $(57.16 \%)$ and all the women belonged to lower socioeconomic strata $(100 \%)$. Maternal mortality was more in women who stayed outside Chittoor town $(51.38 \%)$. Most of these women $(85.72 \%)$ were booked and $42.84 \%$ women were referred from other centers. Majority of patients $(57.16 \%)$ had moderate to severe anaemia during admission to hospital. Many of women were in critical (28.58\%) and serious (28.58\%) conditions, respectively. Table 3-type I $(42.86 \%)$ and type II $(42.86 \%)$ delay were common delays identified.

Table 4 shows causes of maternal deaths which is categorized according to WHO application of ICD-10 to deaths during pregnancy, childbirth and puerperium. ${ }^{6}$ Present study shows obstetric haemorrhage $(57.16 \%)$ is 
major cause of maternal mortality. Other causes of maternal death were due to hypertensive disorders, pulmonary embolism and sepsis which accounted for $42.84 \%$.

Table 2: Socio-demographic characteristics of maternal death.

\begin{tabular}{|c|c|c|}
\hline \multicolumn{2}{|c|}{ Socio-demographic character } & \multirow{2}{*}{$\begin{array}{l}\text { No. of women (\%) } \\
0(0)\end{array}$} \\
\hline \multirow{3}{*}{ Age (year) } & $<20$ & \\
\hline & 20 to 30 & $6(85.72)$ \\
\hline & $>30$ & $1(14.28)$ \\
\hline \multirow{2}{*}{ Parity } & Primipara & $2(28.58)$ \\
\hline & Multipara & $5(71.42)$ \\
\hline \multirow{3}{*}{ Socioeconomic status } & Lower class & $7(100)$ \\
\hline & Middle class & $0(0)$ \\
\hline & Upper class & $0(0)$ \\
\hline \multirow{2}{*}{ literacy } & literate & $3(42.86)$ \\
\hline & illiterate & $4(57.16)$ \\
\hline \multirow{2}{*}{ Residence } & Chittoor town & $1(14.28)$ \\
\hline & Outside Chittoor town & $6(85.72)$ \\
\hline \multirow{2}{*}{ Booking status } & Unbooked & $1(14.28)$ \\
\hline & Booked & $6(85.72)$ \\
\hline \multirow{4}{*}{ Status on admission } & Good & $3(42.86)$ \\
\hline & Fair & $0(0)$ \\
\hline & Serous & $2(28.58)$ \\
\hline & Critical & $2(28.58)$ \\
\hline \multirow{3}{*}{ Prevalence of anaemia } & Severe $(<7$ gm $\%)$ & $2(28.58)$ \\
\hline & Moderate (7-9.9 gm\%) & $2(28.58)$ \\
\hline & Mild (>10 gm\%) & $3(42.86)$ \\
\hline \multirow{2}{*}{ Referral } & Referral & $3(42.84)$ \\
\hline & No referral & $4(57.16)$ \\
\hline
\end{tabular}

Table 3: Type of delays identified contributing to maternal deaths.

Type of delay

Type 1

Type II

Type III

\section{No of deaths $(\%)$}

$3(42.86)$

$3(42.86)$

$1(14.28)$

Table 4: Causes of maternal deaths according to WHO ICD-10.

\begin{tabular}{|lll|}
\hline $\begin{array}{l}\text { Groups according } \\
\text { to ICD-10 code }\end{array}$ & Type and group & $\begin{array}{l}\text { No. of maternal } \\
\text { death }(\%)\end{array}$ \\
\hline $\mathbf{1}$ & Direct: Pregnancies with abortive outcome & 0 \\
\hline $\mathbf{2}$ & Direct: Hypertensive disorders & $1(14.28)$ \\
\hline $\mathbf{3}$ & Direct: Obstetric haemorrhage & $1(57.16)$ \\
$\mathbf{4}$ & Direct: Pregnancy related infections & $(14.28)$ \\
\hline $\mathbf{5}$ & Direct: Other obstetric complications & $1(14.28)$ \\
\hline & Obstructed labor & $0(0)$ \\
\hline $\mathbf{6}$ & $\begin{array}{l}\text { Direct: Unanticipated complications of management (e.g., pulmonary } \\
\text { embolism) }\end{array}$ & \\
\hline & Indirect: Non obstetric complications anaemia & \\
\hline $\mathbf{7}$ & Heart disease (with or without pre-existing hypertension) & \\
\hline $\mathbf{8}$ & Gastrointestinal complications & $0(0)$ \\
\hline $\mathbf{9}$ & Respiratory diseases/ARDS/TB & $0(0)$ \\
\hline
\end{tabular}




\section{DISCUSSION}

A maternal death is defined in the international classification of diseases, $10^{\text {th }}$ edition (ICD-10) as the death of a woman while pregnant or within 42 days upto 1 year for late maternal deaths) of termination of pregnancy, irrespective of the duration and site of the pregnancy, from any cause related to or aggravated by the pregnancy or its management, but not from accidental or incidental causes. $^{7}$

One of the key indicators of maternal mortality is the maternal mortality ratio (MMR) which is defined as the number of maternal deaths during a given time period per $1,00,000$ live births during the same time period. ${ }^{8}$

Maternal mortality is an indicator of the quality of obstetric care in a community directly reflecting the utilization of health care services available. Maternal mortality ratio is a measure of reproductive health of women in the area and quality of health care services available in a country. ${ }^{9}$

Women die as a result of complications during and following pregnancy and childbirth. Most of these complications develop during pregnancy and most are preventable or treatable. Other complications may exist before pregnancy but are worsened during pregnancy, especially if not managed as part of the woman's care. The major complications that account for nearly $75 \%$ of all maternal deaths are severe bleeding (mostly bleeding after childbirth), infections (usually after childbirth), high blood pressure during pregnancy (pre-eclampsia and eclampsia), complications from delivery, unsafe abortion. The remainder are caused by or associated with infections such as malaria or related to chronic conditions like cardiac diseases or diabetes. ${ }^{10}$

The maternal mortality ratio (MMR) in present study is 66 per 1,00,000 live births which is very much lower than national standards of MMR in India that is 113 per 1,00,000 live births during 2016-18 and also below the target of United nations sustainable development goals to reduce maternal mortality ratio to less than 70 per 100 000 live births to be achieved by 2030 . Present study has comparatively lower MMR which could be due to the fact that our hospital is a tertiary care hospital with advanced health care facilities and improved services in spite of receiving a lot of complicated referrals from rural areas.

Similar to majority of the studies, Nove et al states that maternal mortality is more in the extremes of reproductive age group compared to 20-24 years aged women. But in present study maximum maternal deaths were reported in the age group 20 to 30 years. ${ }^{11}$

Multipara patients were more likely under the risk of maternal mortality in present study. Obstetric haemorrhage, which is leading cause of maternal mortality, is commonly seen in multipara patients and hence delivery-care facilities should prepare for emergency situation when attending deliveries of high parity group. $^{12}$

Illiterates and low socioeconomic status patients were under risk of maternal mortality in present study. Women with literacy and middle or high socioeconomic status are more likely to have better knowledge about the possible problems that may arise during pregnancy, will have higher decision-making powers and are likely to be more mobile and avail more of health services such as antenatal care and seek immediate professional medical help in case of complication which in turn could influence the number of maternal mortalities in such societies. $^{13}$

Most of the patients in present study had residence outside Chittoor town $(85.72 \%)$ and had reached our tertiary care centre in serous/critical condition $(57.16 \%)$ with moderate/severe anaemia $(57.16 \%)$ and without referral $(57.6 \%)$. Women's residence far from tertiary care centre has to travel for long distance to reach, unaccompanied by health care worker without referral or referred very late from primary care centre. Pregnant women with haemorrhage can lead to increased blood loss and severe anaemia making the patient critical before reaching hospital and increased maternal mortality.

Most of these deaths are preventable if patients are given appropriate treatment at periphery and timely referred to higher centers. Training of medical officers and staff nurses working in rural areas by programs like basic emergency obstetrics care (BEMOC) and skilled attendant at birth $(\mathrm{SAB})$ training gives a ray of hope of reducing maternal mortality. ${ }^{14}$

In present study, obstetric haemorrhage $(57.16 \%)$ was the leading cause of maternal death followed by hypertensive disorders, sepsis and pulmonary embolism. Findings in present study is similar to that of Doddamani et al. ${ }^{15}$

Most of the maternal mortality in present study is because of type- 1 followed by type- 2 delay. Maternal mortality can be reduced still more extent in our hospital by improving the health care facilities in rural areas, ensuring round the clock availability of certain basic treatment. Early detection of high-risk pregnancies and referring them to a tertiary center at the earliest. Improving the literacy rate and socioeconomic status of the population will help in bringing down maternal mortality to still lower extent.

\section{CONCLUSION}

From present study it can be concluded that along with regular antenatal care and institutional delivery to all pregnant women, following measure can help reduce maternal mortality to still more extent. 
Appropriate referral linkages with stress on early referral, easy transport and with adequate life support measures. Strengthening of existing emergency obstetric care (EmOC) facilities by training and upgradation of medical and paramedical staff and improving infrastructure facilities. Early identification and management of hypertensive disorders in pregnancy. Improving the literacy rate and socioeconomic status of the population.

Funding: No funding sources

Conflict of interest: None declared

Ethical approval: The study was approved by the Institutional Ethics Committee

\section{REFERENCES}

1. Department of health and family welfare, Govt of India. Maternal and adolescent healthcare. Annual Report 2017-2018. 2020;27.

2. Word Health Organization. Maternal mortality. Geneva, Switzerland: Word Health Organization; c2019. cited at 2019. Available from: https://www.who.int/news-room/factsheets/detail/maternal-mortality. Accessed on 10 Oct, 2020.

3. Department of health and family welfare, Govt of India. Maternal and adolescent healthcare. Annual Report 2019-2020. 2020;25.

4. United Nations General Assembly. United Nations Millennium Declaration. A/RES/55/2. 1-9-2000. UN

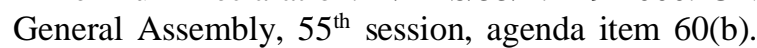
2000.

5. Wani RT. Socioeconomic status scales-modified Kuppuswamy and Udai Pareekh's scale updated for 2019. J Family Med Prim Care. 2019;8:1864-9.

6. World Health Organization. The WHO Application of ICD-10 to Deaths During Pregnancy, Childbirth and the Puerperium: ICD-MM. WHO, 2012.Google Scholar. Available at: https://www.who.int/ reproductivehealth/publications/monitoring/9789241 548458/en/. Accessed on 10 November 2020.

7. World Health Organization, International Classification of Diseases, 10th Revision (ICD-10).
Geneva, Switzerland World Health Organization 1992. Available at: https://www.who.int/ occupational_health/publications/en/oehicd10.pdf?ua $=1$. Accessed on 10 November 2020 .

8. Government of India. Special bulletin on maternal mortality in India 2016-18: Sample registration system. Government of India. Retrieved September 24, 2020, from https://censusindia.gov.in/vital_ statistics/SRS_Bulletins/MMR\%20Bulletin\%202016 -18.pdf. Accessed on 10 Oct, 2020.

9. Juneja Y, Rai U. A five years review of maternal mortality. J Obstet Gynecol India. 1993;43:944-9.

10. Say L, Chou D, Gemmill A, Tunçalp Ö, Moller AB, Daniels JD, et al. Global Causes of Maternal Death: A WHO Systematic Analysis. Lancet Global Health. 2014;2(6):323-33.

11. Nove A, Matthews Z, Neal S, Camacho AV. Maternal mortality in adolescents compared with women of other ages: evidence from 144 countries. Lancet Glob Health. 2014;2(3):e155-64.

12. Muniro Z, Tarimo CS, Mahande MJ, Maro E, Mchome B. Grand multiparity as a predictor of adverse pregnancy outcome among women who delivered at a tertiary hospital in Northern Tanzania. BMC Pregnancy Childbirth. 2019;19(1):222.

13. Haile A, Enqueselassie F. Influence of women's autonomy on couple's contraception use in Jimma town, Ethiopia. Ethiop. J Health Dev. 2006;20(3):145-51

14. Murthy BK, Murthy MB, Prabhu PM. Maternal Mortality in a Tertiary Care Hospital: A 10-year Review. Int J Prev Med. 2013;4(1):105-9.

15. Doddamani U, Rampure N, Kaveri, Pooja. A study of maternal mortality in a tertiary care hospital. Int $\mathbf{J}$ Reprod Contracept Obstet Gynecol. 2018;7:2446-8.

Cite this article as: Harish KM, Shwetha N, Nalini N. Maternal mortality in a tertiary care hospital: a 3year retrospective study. Int J Reprod Contracept Obstet Gynecol 2021;10:474-8. 